\title{
ON THE EFFICIENCIES OF SECOND ORDER RESPONSE SURFACE DESIGNS FOR THE ESTIMATION OF RESPONSES AND SLOPES USING SYMMETRICAL UNEQUAL BLOCK ARRANGEMENTS WITH TWO UNEQUAL BLOCK SIZES
}

\author{
B. Re. Victorbabu* and V. Vasundharadevi**
}

\begin{abstract}
In this paper, the efficiencies of various second order response surface designs, like second order rotatable designs (SORD), second order slope rotatable designs (SOSRD), SORDs with an equi-spaced doses design, and SOSRDs with an equispaced doses design using symmetrical unequal block arrangements (SUBA) with two unequal block sizes, are studied for the estimation of responses and slopes at different points (central, axial, cube corner points) on second order response surface designs. The study is done because in some cases a SORD, and SOSRD constructed by using a SUBA with two unequal block sizes have fewer design points compared to those constructed by other methods.
\end{abstract}

Key words and phrases: Second order response surface designs, second order rotatable designs, second order slope rotatable designs.

\section{Introduction}

Box and Hunter (1957) introduced a series of response surface designs with the property that the variances of estimates of responses at points equi-distance from the centre of the design are all equal. They called these designs rotatable designs when the relationship between the response variable and several input variables is a quadratic or cubic or higher order polynomial. Das and Narasimham (1962) constructed rotatable designs through balanced incomplete block designs (BIBD). Raghavarao (1963) constructed second order rotatable designs (SORD) using incomplete block designs. Dey (1970) studied response surface designs with equi-spaced doses.

The study of rotatable designs mainly emphasizes the estimation of the absolute response. Estimation of differences in responses at two different points in the factor space will often be of great importance. In the case of differences at two points close together, estimation of the local slope (rate of change) of the response is of interest. Estimation of slopes occurs frequently in practical situations. For instance, there are cases in which we want to estimate the rate of reaction in a chemical experiment, the rate of change in the yield of a crop to

\footnotetext{
Received January 6, 2005. Revised September 11, 2005. Accepted June 5, 2008.

*Professor of Statistics, Department of Statistics, Acharya Nagarjuna University, Guntur -522 510, Andhra Pradesh, India.

**Research Scholar, Department of Statistics, Acharya Nagarjuna University, Guntur -522 510, Andhra Pradesh, India.
} 
various fertilizer doses, the rate of disintegration of a radioactive material in an animal etc.

Hader and Park (1978) introduced slope rotatable central composite designs. Victorbabu and Narasimham (1991) constructed second order slope rotatable designs (SOSRD) using BIBD. Victorbabu et al. (1994) constructed SOSRDs with equi-spaced levels using incomplete block designs with unequal block sizes. Victorbabu (2002a) studied SOSRDs with equi-spaced levels. Victorbabu (2002b) constructed SOSRDs using symmetrical unequal block arrangements with two unequal block sizes. Victorbabu and Vasundharadevi (2004) studied the efficiencies of second order response surface designs for the estimation of responses and slopes using BIBD.

In this paper, the efficiencies of various second order response surface designs like SORDs, SOSRDs, SORDs with an equi-spaced doses design, and SOSRDs with an equi-spaced doses design using symmetrical unequal block arrangement with two unequal block sizes are studied for the estimation of responses and slopes at different points (central, axial, cube corner points) on second order response surface designs.

\section{Some Preliminaries Regarding Response Surface Designs}

A design for fitting a response surface consists of a number of suitable combinations of levels of several input factors. We shall use ' $v$ ' for the number of factors and ' $N$ ' for the number of combinations in the design, each factor having a constant number of levels. A response surface design can be written as $v$ rows and $N$ columns each. Each row is a combination of $v$-level codes, one from each of $v$-ordered factors. A combination of level codes is also called a design point. The combination with 0-code for each factor is called a central point.

Suppose we want to use the second order response surface design $D=\left(\left(x_{i u}\right)\right)$ to fit the surface,

$$
Y_{u}=b_{0}+\sum_{i=1}^{v} b_{i} x_{i u}+\sum_{i=1}^{v} b_{i i} x_{i u}^{2}+\sum \sum_{i<j} b_{i j} x_{i u} x_{j u}+e_{u}
$$

where $x_{i u}$ denotes the level of the $i$-th factor $(i=1,2, \ldots, v)$ in the $u$-th run $(u=1,2, \ldots, N)$ of the experiment, and $e_{u}$ 's are uncorrelated random errors with mean zero and variance $\sigma^{2}$.

Here $b_{0}, b_{i}, b_{i i}, b_{i j}$ are the parameters of the model and $Y_{u}$ is the response observed at the $u$-th design point. The parameters in the response relation are estimated using the least squares technique. Further we impose the following simple symmetry conditions on the design points to simplify the solutions of the normal equations.

$$
\sum_{u=1}^{N} \prod_{i=1}^{v} x_{i u}^{\alpha_{i}}=0, \quad \text { if any } \alpha_{i} \text { is odd, for } \quad \sum \alpha_{i} \leq 4
$$


(i) $\sum_{u=1}^{N} x_{i u}^{2}=$ constant $=N \lambda_{2}$,

(ii) $\quad \sum_{u=1}^{N} x_{i u}^{4}=$ constant $=c N \lambda_{4}, \quad$ for all $i$,

$\sum_{u=1}^{N} x_{i u}^{2} x_{j u}^{2}=$ constant $=N \lambda_{4}, \quad$ for $\quad i \neq j$,

where $c, \lambda_{2}$ and $\lambda_{4}$ are constants. Using these symmetry conditions we obtain the estimates of the parameters as

$$
\begin{aligned}
\hat{b}_{0} & =\frac{\lambda_{4}(c+v-1) \sum_{u} Y_{u}-\lambda_{2} \sum_{i}\left(\sum_{u} x_{i u}^{2} Y_{u}\right)}{N\left[\lambda_{4}(c+v-1)-v \lambda_{2}^{2}\right]}, \\
\hat{b}_{i} & =\frac{\sum_{u} x_{i u} Y_{u}}{N \lambda_{2}} \quad(i=1,2, \ldots, v), \\
\hat{b}_{i j} & =\frac{\sum_{u} x_{i u} x_{j u} Y_{u}}{N \lambda_{4}}(i \neq j=1,2, \ldots, v), \\
\hat{b}_{i i} & =\frac{\sum_{u} x_{i u}^{2} Y_{u}}{(c-1) N \lambda_{4}}-\frac{\lambda_{2} \lambda_{4}(c-1) \sum_{u} Y_{u}-\sum_{i}\left(\sum_{u} x_{i u}^{2} Y_{u}\right)\left(\lambda_{2}^{2}-\lambda_{4}\right)}{(c-1) N \lambda_{4}\left[\lambda_{4}(c+v-1)-v \lambda_{2}^{2}\right]} .
\end{aligned}
$$

Using these solutions, variances and covariances of these estimates are given below:

$$
\begin{aligned}
& V\left(\hat{b}_{0}\right)=\frac{\lambda_{4}(c+v-1) \sigma^{2}}{N\left[\lambda_{4}(c+v-1)-v \lambda_{2}^{2}\right]}, \\
& V\left(\hat{b}_{i}\right)=\frac{\sigma^{2}}{N \lambda_{2}}, \\
& V\left(\hat{b}_{i j)}=\frac{\sigma^{2}}{N \lambda_{4}},\right. \\
& V\left(\hat{b}_{i i}\right)=\frac{\sigma^{2}}{(c-1) N \lambda_{4}}\left[\frac{\lambda_{4}(c+v-2)-(v-1) \lambda_{2}^{2}}{\lambda_{4}(c+v-1)-v \lambda_{2}^{2}}\right], \\
& \operatorname{Cov}\left(\hat{b}_{0}, \hat{b}_{i i}\right)=\frac{-\lambda_{2} \sigma^{2}}{N\left[\lambda_{4}(c+v-1)-v \lambda_{2}^{2}\right]}, \\
& \operatorname{Cov}\left(\hat{b}_{i i}, \hat{b}_{j j}\right)=\frac{\left(\lambda_{2}^{2}-\lambda_{4}\right) \sigma^{2}}{(c-1) N \lambda_{4}\left[\lambda_{4}(c+v-1)-v \lambda_{2}^{2}\right]},
\end{aligned}
$$

and other covariances are zero.

An inspection of the variances shows that a necessary condition for the existence of a non-singular second order design is $\lambda_{4}(c+v-1)-v \lambda_{2}^{2}>0$, which leads to the condition

$$
\frac{\lambda_{4}}{\lambda_{2}^{2}}>\frac{v}{c+v-1}(\text { Non-singularity condition }) .
$$

Using these variances and covariances, the variance of the estimated response at any point can be obtained. Let $\hat{Y}_{u}$ denote the response at the point 
$\left(x_{1 u}, x_{2 u}, \ldots, x_{v u}\right)$ as estimated using the response relation. Then

$$
\begin{aligned}
V\left(\hat{Y}_{u}\right)= & V\left(\hat{b}_{0}\right)+d_{u}^{2}\left[V\left(\hat{b}_{i}\right)+2 \operatorname{Cov}\left(\hat{b}_{0}, \hat{b}_{i i}\right)\right] \\
& +d_{u}^{4} V\left(\hat{b}_{i i}\right)+\sum_{i \neq j} x_{i u}^{2} x_{j u}^{2}\left[(c-3) \sigma^{2} /(c-1) N \lambda_{4}\right] .
\end{aligned}
$$

From equation (1.7), it is clear that if $c=3$ by a suitable choice of the design, the coefficient of $\sum x_{i u}^{2} x_{j u}^{2}$ vanishes and the variance becomes a function of the distance $\left(d_{u}^{2}=\sum_{i=1}^{v} x_{i u}^{2}\right)$ (the distance of the $u$-th design point from the origin) only, viz.

$$
V\left(\hat{Y}_{u}\right)=V\left(\hat{b}_{0}\right)+d_{u}^{2}\left[V\left(\hat{b}_{i}\right)+2 \operatorname{Cov}\left(\hat{b}_{0}, \hat{b}_{i i}\right)\right]+d_{u}^{4} V\left(\hat{b}_{i i}\right) .
$$

\section{Definition of Second Order Rotatable Design (SORD):}

A second order response surface design $D$ is said to be an SORD, if in this design $c=3, \sum_{u=1}^{N} x_{i u}^{4}=3 \sum_{u=1}^{N} x_{i u}^{2} x_{j u}^{2}$ and all the other conditions (1.2), (1.3), (1.4) and (1.6) hold. Hence the variance of the estimated response of $Y_{u}$ from the fitted surface is only a function of the distance $\left(d^{2}=\sum_{i=1}^{v} x_{i u}^{2}\right)$ of the point $\left(x_{1 u}, x_{2 u}, \ldots, x_{v u}\right)$ from the origin (center) of the design (cf. Box and Hunter (1957)).

\section{Slope Rotatable Designs:}

For the second order response surface design given in equation (1.1), we have

$$
\frac{\partial \hat{Y}_{u}}{\partial x_{i}}=\hat{b}_{i}+2 \hat{b}_{i i} x_{i u}+\sum_{j \neq i} \hat{b}_{i j} x_{j u}
$$

and

$$
V\left(\frac{\partial \hat{Y}_{u}}{\partial x_{i}}\right)=V\left(\hat{b}_{i}\right)+4 x_{i u}^{2} V\left(\hat{b}_{i i}\right)+\sum_{j \neq i} x_{j u}^{2} V\left(\hat{b}_{i j}\right) .
$$

The condition for the right hand side of equation (1.10) to be a function of the distance $\left(d_{u}^{2}=\sum_{i=1}^{v} x_{i u}^{2}\right)$ alone (for the slope rotatability) is

$$
4 V\left(\hat{b}_{i i}\right)=V\left(\hat{b}_{i j}\right) .
$$

Therefore, conditions (1.2) to (1.6) and (1.11) lead to the condition

$$
\left[v(5-c)-(c-3)^{2}\right] \lambda_{4}+[v(c-5)+4] \lambda_{2}^{2}=0 .
$$

\section{Definition of Second Order Slope Rotatable Design (SOSRD):}

A second order response surface design $D$ is said to be an SOSRD if the variance of the estimate of the first order partial derivative $\left(\partial \hat{Y}_{u} / \partial x_{i}\right)$ with respect to each of the independent variables $\left(x_{i}\right)$ is only a function of the distance $\left(d^{2}=\right.$ $\left.\sum_{i=1}^{v} x_{i u}^{2}\right)$ of the point $\left(x_{1 u}, x_{2 u}, \ldots, x_{v u}\right)$ from the origin (center) of the design. Such a spherical variance function for the estimation of slopes in the second order response surface is achieved if the design points satisfy the conditions (1.2), (1.3), (1.4), (1.6) and (1.12) (cf. Hader and Park (1978), Victorbabu and Narasimham $(1991))$. 


\section{SUBA with two unequal block sizes (cf. Raghavarao, 1962):}

Let $v$-treatments $1,2, \ldots, v$ satisfy the following relations:

(a) Any two treatments are either the 1st or 2nd block associates, the relation of the block association being symmetrical, i.e., if treatment $\theta$ is the $i$-th block associate of $\phi$, then $\phi$ is the $i$-th block associate of $\theta$.

(b) Each treatment $\theta$ has $\mu_{i}$, $i$-th block associates, the number $\mu_{i}$ being independent of $\theta$.

(c) If any two treatments $\theta$ and $\phi$ are $i$-th block associates, then the number of treatments which are $j$-th block associates of $\theta$ and $k$-th block associates of $\phi$ is $p_{i j k}$, and is independent of the pair of $i$-th block associates $\theta$ and $\phi$. Also $p_{i j k}=p_{i k j}$.

\section{Definition of SUBA with two unequal block sizes:}

The arrangement of $v$-treatments, satisfying the above conditions, in $b$ blocks where $b_{1}$ blocks of size $k_{1}$ and $b_{2}$ blocks of size $k_{2}\left(b_{1}+b_{2}=b\right)$, is said to be a symmetrical unequal block arrangement with two unequal block sizes if

(i) every treatment occurs in $\frac{b_{i} k_{i}}{v}$ blocks of size $k_{i}(i=1,2)$, and

(ii) every pair of first associate treatments occurs together in $u$ blocks of size $k_{1}$ and in $(\lambda-u)$ blocks of size $k_{2}$, while every pair of second associate treatments occurs together in $\lambda$ blocks of size $k_{2}$.

From (i) each treatment occurs in $\left(\frac{b_{1} k_{1}}{v}\right)+\left(\frac{b_{2} k_{2}}{v}\right)=r$ blocks in all. $(v, b, r$, $\left.k_{1}, k_{2}, b_{1}, b_{2}, \lambda\right)$ are known as the parameters of the SUBA with two unequal block sizes.

Let there be a SUBA with two unequal block sizes with the parameters $\left(v, b, r, k_{1}, k_{2}, b_{1}, b_{2}, \lambda\right)$ and $k=\sup \left(k_{1}, k_{2}\right)$. Let us write the design in the form of a $b \times v$ matrix, the elements of which are zero and $\alpha$. If in any block a particular treatment occurs, the element in that block corresponding to that treatment will be $\alpha$, otherwise, zero. We denote these design points generated from the transpose of the incidence matrix of an SUBA with two unequal block sizes by $\left[\alpha-\left(v, b, r, k_{1}, k_{2}, b_{1}, b_{2}, \lambda\right)\right]$. Let $2^{t(k)}$ denote the number of design points of a fractional factorial design of $2^{k}$ in \pm 1 levels, such that no interaction with less than five factors is confounded. $\left[\alpha-\left(v, b, r, k_{1}, k_{2}, b_{1}, b_{2}, \lambda\right)\right] 2^{t(k)}$ are the $b 2^{t(k)}$ design points generated from the SUBA with two unequal block sizes by 'multiplication' (cf. Raghavarao (1971), pp. 298-300), ( $\pm \beta, 0,0, \ldots, 0) 2^{1}$ denotes the design points generated from $( \pm \beta, 0,0, \ldots, 0)$ point set, $\cup$ denotes the union of the design points generated from different sets of points and $\left(n_{0}\right)$ is the number of central points in the design.

RESUlt. Construction of SOSRD using a SUBA with two unequal block sizes (Victorbabu (2002b)): Consider the SUBA $\left(v, b, r, k_{1}, k_{2}, b_{1}, b_{2}, \lambda\right)$ with two unequal block sizes. Then the design points $\left[\alpha-\left(v, b, r, k_{1}, k_{2}, b_{1}, b_{2}, \lambda\right)\right] 2^{t(k)} \cup$ $(\beta, 0,0, \ldots, 0) 2^{1} \cup\left(n_{0}\right)$ give a $v$-dimensional SOSRD in $N=b 2^{t(k)}+2 v+n_{0}$ design points, where $(\beta / \alpha)^{2}$ is a positive real root of the equation 


$$
\begin{aligned}
(8 v-4 N) & (\beta / \alpha)^{8}+8 v r 2^{t(k)}(\beta / \alpha)^{6} \\
+ & {\left[2 v r^{2} 2^{2 t(k)}+\{((12-2 v) \lambda-4 r) N\right.} \\
& \left.+(16 \lambda-20 v \lambda+4 v r)\} 2^{t(k)}\right](\beta / \alpha)^{4} \\
+ & {\left[4 v r^{2}+(16-20 v) r \lambda\right] 2^{2 t(k)}(\beta / \alpha)^{2} } \\
+ & {\left[(5 v-9) \lambda^{2}+(6-v) r \lambda-r^{2}\right] N 2^{2 t(k)} } \\
+ & (v r+4 \lambda-5 v \lambda) r^{2} 2^{3 t(k)}=0 .
\end{aligned}
$$

If at least one positive real root exists for equation (1.13) then the design exists.

\section{Equi-spaced doses designs:}

The SORD/SOSRD is not generally available with equi-spaced doses (levels). Though designs with equi-spaced levels are not necessary, they are likely to be preferred in view of the case in handling the doses. Further in SORD/SOSRD, the calculation of the actual doses often requires approximations and hence actual dose levels can not be applied in practice. For example, in Agriculture experiments, the factors may have equi-spaced doses. The response surface designs with $v$-factors each having equi-spaced doses may be obtained by using a SUBA with two unequal block sizes as follows:

Consider the following sets of points: (i) $b 2^{t(k)}$ points obtained through the incidence matrix of a SUBA with two unequal block sizes $\left[\alpha-\left(v, b, r, k_{1}, k_{2}\right.\right.$, $\left.\left.b_{1}, b_{2}, \lambda\right)\right] 2^{t(k)}$, (ii) $2 v$ axial points $( \pm \beta, 0,0, \ldots, 0)$ etc., The corresponding equispaced doses design is obtained by changing the axial points from $( \pm \beta, 0,0, \ldots, 0)$ etc., to $( \pm 2 \alpha, 0,0, \ldots, 0)$-repeated ' $y$ ' times and (iii) $n_{0}$-central points. Thus we note the levels of factors used in these design points are $-2 \alpha,-\alpha, 0, \alpha, 2 \alpha$.

\section{Estimation of responses and slopes using a SUBA with two unequal block sizes}

Consider a SUBA $\left(v, b, r, k_{1}, k_{2}, b_{1}, b_{2}, \lambda\right)$ with two unequal block sizes and $k=\sup \left(k_{1}, k_{2}\right)$. Then the design points $\left[\alpha-\left(v, b, r, k_{1}, k_{2}, b_{1}, b_{2}, \lambda\right)\right] 2^{t(k)} \cup$ $(\beta, 0,0, \ldots, 0) 2^{1} \cup\left(n_{0}\right)$ give a $v$-dimensional SORD/SOSRD in $N=b 2^{t(k)}+2 v+n_{0}$ design points. The unknown levels are obtained by using conditions (1.2) to (1.6), $\sum x_{i u}^{4}=3 \sum x_{i u}^{2} x_{j u}^{2}$ for Box and Hunter (1957) rotatability, and (1.2) to (1.6), (1.12) for Hader and Park (1978) slope rotatability.

2.1. $V\left(\hat{Y}_{u}\right)$ and $V\left(\frac{\partial \hat{Y}_{u}}{\partial x_{i}}\right)$ in SORD at the central point

From equations (1.3) and (1.4), we have

$$
\begin{aligned}
& \sum x_{i u}^{2}=r 2^{t(k)} \alpha^{2}+2 \beta^{2}=N \lambda_{2}, \\
& \sum x_{i u}^{4}=r 2^{t(k)} \alpha^{4}+2 \beta^{4}=3 N \lambda_{4}, \\
& \sum x_{i u}^{2} x_{j u}^{2}=\lambda 2^{t(k)} \alpha^{4}=N \lambda_{4} .
\end{aligned}
$$


Taking $\lambda_{2}=1$ (called a scaling condition for comparison of two designs for the same ' $v$ ') and on simplification, we get

$$
\begin{aligned}
& \alpha=\sqrt{\frac{N}{r 2^{t(k)}+2^{(t(k)+1) / 2}(3 \lambda-r)^{1 / 2}}}, \\
& \beta^{4}=2^{t(k)-1}(3 \lambda-r) \alpha^{4} \\
& V\left(\hat{Y}_{u}\right)=V\left(\hat{b}_{0}\right)=\frac{\lambda_{4}(c+v-1) \sigma^{2}}{N\left[\lambda_{4}(c+v-1)-v\right]} \quad \text { (from equation (1.8)). }
\end{aligned}
$$

Simplifying equation (2.6) by taking $c=3$, we get

$$
\begin{aligned}
& V\left(\hat{Y}_{u}\right)=\frac{\lambda_{4}(v+2) \sigma^{2}}{N\left[\lambda_{4}(v+2)-v\right]}, \\
& V\left(\frac{\partial \hat{Y}_{u}}{\partial x_{i}}\right)=V\left(\hat{b}_{i}\right)=\frac{\sigma^{2}}{N} \quad(\text { from equation }(1.10)) .
\end{aligned}
$$

\section{2. $V\left(\hat{Y}_{u}\right)$ and $V\left(\frac{\partial \hat{Y}_{u}}{\partial x_{i}}\right)$ in SOSRD at the central point}

The estimate of the slope in the second order model and its variances are obtained by equations (1.9) and (1.10). The required levels $\alpha, \beta$ in SOSRD using a SUBA with two unequal block sizes can be obtained as follows (cf. Victorbabu $(2002 b))$ :

From the conditions (1.3) and (1.4), we have

$$
\begin{aligned}
& \sum x_{i u}^{2}=r 2^{t(k)} \alpha^{2}+2 \beta^{2}=N \lambda_{2}, \\
& \sum x_{i u}^{4}=r 2^{t(k)} \alpha^{4}+2 \beta^{4}=c N \lambda_{4}, \\
& \sum x_{i u}^{2} x_{j u}^{2}=\lambda 2^{t(k)} \alpha^{4}=N \lambda_{4} .
\end{aligned}
$$

From equations (2.10) and (2.11), we get $c=\frac{r 2^{t(k)} \alpha^{4}+2 \beta^{4}}{\lambda 2^{t(k)} \alpha^{4}}$. Substituting for $\lambda_{2}, \lambda_{4}$ and $\mathrm{c}$ in the slope rotatability condition (1.12) and on simplification, we get the biquadratic equation given in equation (1.13). We obtain $V\left(\hat{Y}_{u}\right)$ and $V\left(\frac{\partial \hat{Y}_{u}}{\partial x_{i}}\right)$ at the central point as follows:

$$
\begin{aligned}
V\left(\hat{Y}_{u}\right) & =V\left(\hat{b}_{0}\right)=\frac{\lambda_{4}(c+v-1) \sigma^{2}}{N\left[\lambda_{4}(c+v-1)-v \lambda_{2}^{2}\right]} \\
& =\frac{\lambda_{4}(c+v-1) \sigma^{2}}{N\left[\lambda_{4}(c+v-1)-v\right]}\left(\text { taking } \lambda_{2}=1\right), \\
V\left(\frac{\partial \hat{Y}_{u}}{\partial x_{i}}\right) & =V\left(\hat{b}_{i}\right)=\frac{\sigma^{2}}{N \lambda_{2}}=\frac{\sigma^{2}}{N} .
\end{aligned}
$$

2.3. $V\left(\hat{Y}_{u}\right)$ and $V\left(\frac{\partial \hat{Y}_{u}}{\partial x_{i}}\right)$ in an equi-spaced doses SORD at the central point

Following Dey (1970), an equi-spaced doses second order rotatable design (EDSORD) using a SUBA with two unequal block sizes can be obtained by 
considering the following design points, (i) $b 2^{t(k)}$ points obtained through the incidence matrix of a SUBA with two unequal block sizes, (ii) $2 v$ axial points viz., $( \pm 2 \alpha, 0,0, \ldots, 0)$ etc., repeated ' $y$ ' times and (iii) $n_{0}$-central points. Then the design points $\left[\alpha-\left(v, b, r, k_{1}, k_{2}, b_{1}, b_{2}, \lambda\right)\right] 2^{t(k)} \cup y( \pm 2 \alpha, 0,0, \ldots, 0) 2^{1} \cup\left(n_{0}\right)$ give a $v$-dimensional SORD with equi-spaced levels in $N=b 2^{t(k)}+2 y v+n_{0}$ design points. These design points are determined so that they satisfy conditions (1.2), (1.3) and (1.4). From equations (1.3) and (1.4), we have

$$
\begin{aligned}
& \sum x_{i u}^{2}=r 2^{t(k)} \alpha^{2}+8 y \alpha^{2}=N \lambda_{2}, \\
& \sum x_{i u}^{4}=r 2^{t(k)} \alpha^{4}+32 y \alpha^{4}=3 N \lambda_{4}, \\
& \sum x_{i u}^{2} x_{j u}^{2}=\lambda 2^{t(k)} \alpha^{4}=N \lambda_{4} .
\end{aligned}
$$

From equations (2.15) and (2.16), we get $y=(3 \lambda-r) 2^{t(k)-5}$. Taking $\lambda_{2}=1$ in equation (2.14), we can find $\alpha$. We thus get the variances of estimates of responses and slopes at the central point as $V\left(\hat{Y}_{u}\right)=V\left(\hat{b}_{0}\right)$ and $V\left(\frac{\partial \hat{Y}_{u}}{\partial x_{i}}\right)=V\left(\hat{b}_{i}\right)$.

\section{4. $V\left(\hat{Y}_{u}\right)$ and $V\left(\frac{\partial \hat{Y}_{u}}{\partial x_{i}}\right)$ in an equi-spaced doses SOSRD at the central point}

Following Victorbabu et al. (1994) and Victorbabu (2002a), an equi-spaced doses second order slope rotatable design (EDSOSRD) can be obtained by considering the following design points, (i) $b 2^{t(k)}$ points obtained through the incidence matrix of an SUBA with two unequal block sizes, (ii) $2 v$ axial points, viz., $( \pm 2 \alpha, 0,0, \ldots, 0)$-repeated ' $y$ '-times, and (iii) $n_{0}$-central points. Then the design points $\left[\alpha-\left(v, b, r, k_{1}, k_{2}, b_{1}, b_{2}, \lambda\right)\right] 2^{t(k)} \cup y( \pm 2 \alpha, 0,0, \ldots, 0) 2^{1} \cup\left(n_{0}\right)$ give a $v$-dimensional SOSRD with equi-spaced levels in $N=b 2^{t(k)}+2 y v+n_{0}$ design points, if

$$
\begin{aligned}
& y=(c \lambda-r) 2^{t(k)-5}, \\
& n_{0}=\frac{(c \lambda+3 r)^{2}[v(5-c)-4] 2^{t(k)-4}}{\lambda\left[v(5-c)-(c-3)^{2}\right]}-\left(b 2^{t(k)}+2 y v\right)
\end{aligned}
$$

and $n_{0}$ turns out to be an integer.

For the design points generated from SUBA with two unequal block sizes, conditions (1.2), (1.3), and (1.4) hold. Hence,

$$
\begin{aligned}
& \sum x_{i u}^{2}=r 2^{t(k)} \alpha^{2}+8 y \alpha^{2}=N \lambda_{2}, \\
& \sum x_{i u}^{4}=r 2^{t(k)} \alpha^{4}+32 y \alpha^{4}=c N \lambda_{4}, \\
& \sum x_{i u}^{2} x_{j u}^{2}=\lambda 2^{t(k)} \alpha^{4}=N \lambda_{4} .
\end{aligned}
$$

We have $\sum x_{i u}^{4}=c \sum x_{i u}^{2} x_{j u}^{2}$ which leads to ' $y$ ' given in (2.17). From the slope rotatability condition (1.12), we get $n_{0}$. The value of ' $\alpha$ ' can be obtained from the scaling condition. We thus get the variances of estimates of responses and slopes at the central point as $V\left(\hat{Y}_{u}\right)=V\left(\hat{b}_{0}\right)$ and $V\left(\frac{\partial \hat{Y}_{u}}{\partial x_{i}}\right)=V\left(\hat{b}_{i}\right)$. 
2.5. $V\left(\hat{Y}_{u}\right)$ and $V\left(\frac{\partial \hat{Y}_{u}}{\partial x_{i}}\right)$ in SORD at axial points

Here we evaluate $V\left(\hat{Y}_{u}\right)$ and $V\left(\frac{\partial \hat{Y}_{u}}{\partial x_{i}}\right)$ at the axial points in SORD as follows:

$$
\begin{aligned}
& V\left(\hat{Y}_{u}\right)=V\left(\hat{b}_{0}\right)+p^{2}\left[V\left(\hat{b}_{i}\right)+2 \operatorname{Cov}\left(\hat{b}_{0}, \hat{b}_{i i}\right)\right]+p^{4} V\left(\hat{b}_{i i}\right), \\
& V\left(\frac{\partial \hat{Y}_{u}}{\partial x_{i}}\right)=V\left(\hat{b}_{i}\right)+4 p^{2} V\left(\hat{b}_{i i}\right),
\end{aligned}
$$

where in the axial point $x_{i}= \pm p$, other coordinates are zero.

2.6. $V\left(\hat{Y}_{u}\right)$ and $V\left(\frac{\partial \hat{Y}_{u}}{\partial x_{i}}\right)$ in SOSRD at axial points

Here variances of estimates of responses and slopes at axial points like $( \pm p, 0, \ldots, 0),(0, \pm p, 0, \ldots, 0), \ldots,(0,0, \ldots, \pm p)$ are obtained as follows:

$$
\begin{aligned}
& V\left(\hat{Y}_{u}\right)=V\left(\hat{b}_{0}\right)+p^{2}\left[V\left(\hat{b}_{i}\right)+2 \operatorname{Cov}\left(\hat{b}_{0}, \hat{b}_{i i}\right)\right]+p^{4} V\left(\hat{b}_{i i}\right) \\
& V\left(\frac{\partial \hat{Y}_{u}}{\partial x_{i}}\right)=\frac{1}{N}\left[\frac{\lambda_{4}+\lambda_{2} p^{2}}{\lambda_{2} \lambda_{4}}\right] \sigma^{2}=\frac{1}{N}\left[1+\frac{p^{2}}{\lambda_{4}}\right] \sigma^{2} \quad\left(\text { taking } \lambda_{2}=1\right) .
\end{aligned}
$$

2.7. $V\left(\hat{Y}_{u}\right)$ and $V\left(\frac{\partial \hat{Y}_{u}}{\partial x_{i}}\right)$ for an equi-spaced doses SORD at axial points

Here we find the variances of estimates of responses and slopes as follows:

$$
\begin{aligned}
& V\left(\hat{Y}_{u}\right)=V\left(\hat{b}_{0}\right)+p^{2}\left[V\left(\hat{b}_{i}\right)+2 \operatorname{Cov}\left(\hat{b}_{0}, \hat{b}_{i i}\right)\right]+p^{4} V\left(\hat{b}_{i i}\right), \\
& V\left(\frac{\partial \hat{Y}_{u}}{\partial x_{i}}\right)=V\left(\hat{b}_{i}\right)+4 x_{i u}^{2} V\left(\hat{b}_{i i}\right)+\sum_{j \neq i} x_{j u}^{2} V\left(\hat{b}_{i j}\right),
\end{aligned}
$$

at $(0,0, \ldots, \pm p, 0,0)$ with $x_{i}= \pm p$.

2.8. $V\left(\hat{Y}_{u}\right)$ and $V\left(\frac{\partial \hat{Y}_{u}}{\partial x_{i}}\right)$ for an equi-spaced doses SOSRD at axial points Here we find the variances of estimates of responses and slopes as follows:

$$
\begin{aligned}
& V\left(\hat{Y}_{u}\right)=V\left(\hat{b}_{0}\right)+p^{2}\left[V\left(\hat{b}_{i}\right)+2 \operatorname{Cov}\left(\hat{b}_{0}, \hat{b}_{i i}\right)\right]+p^{4} V\left(\hat{b}_{i i}\right), \\
& V\left(\frac{\partial \hat{Y}_{u}}{\partial x_{i}}\right)= V\left(\hat{b}_{i}\right)+4 p^{2} V\left(\hat{b}_{i i}\right) \\
&= \frac{\sigma^{2}}{N \lambda_{2}}+\frac{4 p^{2} \sigma^{2}}{(c-1) N \lambda_{4}}\left[1+\frac{\left(\lambda_{2}^{2}-\lambda_{4}\right)}{\lambda_{4}(c+v-1)-v \lambda_{2}^{2}}\right] \\
&= \frac{\sigma^{2}}{N}+\frac{4 p^{2} \sigma^{2}}{(c-1) N \lambda_{4}} \\
& \times\left[1+\frac{\left(1-\lambda_{4}\right)}{\lambda_{4}(c+v-1)-v}\right] \quad\left(\text { taking } \lambda_{2}=1\right) .
\end{aligned}
$$


2.9. $V\left(\hat{Y}_{u}\right)$ and $V\left(\frac{\partial \hat{Y}_{u}}{\partial x_{i}}\right)$ in SORD at cube corner points

Here we evaluate $V\left(\hat{Y}_{u}\right)$ and $V\left(\frac{\partial \hat{Y}_{u}}{\partial x_{i}}\right)$ at cube corner points like $( \pm p, \pm p, \ldots$, $\pm p)$ in SORD as follows:

$$
\begin{aligned}
& V\left(\hat{Y}_{u}\right)=V\left(\hat{b}_{0}\right)+v p^{2}\left[V\left(\hat{b}_{i}\right)+2 \operatorname{Cov}\left(\hat{b}_{0}, \hat{b}_{i i}\right)\right]+v^{2} p^{4} V\left(\hat{b}_{i i}\right), \\
& V\left(\frac{\partial \hat{Y}_{u}}{\partial x_{i}}\right)=V\left(\hat{b}_{i}\right)+4 p^{2} V\left(\hat{b}_{i i}\right) .
\end{aligned}
$$

2.10. $V\left(\hat{Y}_{u}\right)$ and $V\left(\frac{\partial \hat{Y}_{u}}{\partial x_{i}}\right)$ in SOSRD at cube corner points

Here we obtain $V\left(\hat{Y}_{u}\right)$ and $V\left(\frac{\partial \hat{Y}_{u}}{\partial x_{i}}\right)$ at cube corner points in SOSRD as follows:

$$
\begin{aligned}
& V\left(\hat{Y}_{u}\right)=V\left(\hat{b}_{0}\right)+p^{2}\left[V\left(\hat{b}_{i}\right)+2 \operatorname{Cov}\left(\hat{b}_{0}, \hat{b}_{i i}\right)\right]+p^{4} V\left(\hat{b}_{i i}\right) \\
& V\left(\frac{\partial \hat{Y}_{u}}{\partial x_{i}}\right)=\frac{1}{N}\left[\frac{\lambda_{4}+\lambda_{2} p^{2}}{\lambda_{2} \lambda_{4}}\right] \sigma^{2}=\frac{1}{N}\left[1+\frac{p^{2}}{\lambda_{4}}\right] \sigma^{2}\left(\text { taking } \lambda_{2}=1\right)
\end{aligned}
$$

2.11. $V\left(\hat{Y}_{u}\right)$ and $V\left(\frac{\partial \hat{Y}_{u}}{\partial x_{i}}\right)$ in equi-spaced doses SORD at cube corner points

Here we find the variances of estimates of responses and slopes at cube corner points.

$$
\begin{aligned}
V\left(\hat{Y}_{u}\right)=V\left(\hat{b}_{0}\right)+p^{2}\left[V\left(\hat{b}_{i}\right)+2 \operatorname{Cov}\left(\hat{b}_{0}, \hat{b}_{i i}\right)\right]+p^{4} V\left(\hat{b}_{i i}\right), \\
\begin{aligned}
& V\left(\frac{\partial \hat{Y}_{u}}{\partial x_{i}}\right)= V\left(\hat{b}_{i}\right)+4 x_{i u}^{2} V\left(\hat{b}_{i i}\right)+\sum_{j \neq i} x_{j u}^{2} V\left(\hat{b}_{i j}\right) \\
&= \frac{\sigma^{2}}{N \lambda_{2}}+\frac{p^{2} \sigma^{2}}{N \lambda_{4}} \\
& \times\left[\frac{4}{c-1}\left\{\frac{\lambda_{4}(c+v-2)-(v-1) \lambda_{2}^{2}}{\lambda_{4}(c+v-1)-v \lambda_{2}^{2}}\right\}+(v-1)\right] \\
&= \frac{\sigma^{2}}{N}+\frac{p^{2} \sigma^{2}}{N \lambda_{4}}\left[\frac{4}{c-1}\left\{\frac{\lambda_{4}(c+v-2)-(v-1)}{\lambda_{4}(c+v-1)-v}\right\}+(v-1)\right] \\
&\left(\text { taking } \lambda_{2}=1\right) .
\end{aligned}
\end{aligned}
$$

2.12. $V\left(\hat{Y}_{u}\right)$ and $V\left(\frac{\partial \hat{Y}_{u}}{\partial x_{i}}\right)$ in equi-spaced doses SOSRD at cube corner points

Here we find the variances of estimates of responses and slopes at cube corner points.

$$
\begin{aligned}
& V\left(\hat{Y}_{u}\right)=V\left(\hat{b}_{0}\right)+v p^{2}\left[V\left(\hat{b}_{i}\right)+2 \operatorname{Cov}\left(\hat{b}_{0}, \hat{b}_{i i}\right)\right]+v^{2} p^{4} V\left(\hat{b}_{i i}\right), \\
& V\left(\frac{\partial \hat{Y}_{u}}{\partial x_{i}}\right)=V\left(\hat{b}_{i}\right)+4 p^{2} V\left(\hat{b}_{i i}\right) .
\end{aligned}
$$




\section{Comparison of efficiencies of different second order designs for the estimation of responses and slopes}

The variances of estimates of responses and slopes at (i) Central point $(0,0, \ldots, 0)$, (ii) Axial points $( \pm p, 0, \ldots, 0),(0, \pm p, 0, \ldots, 0), \ldots,(0,0, \ldots, \pm p)$ and (iii) Cube Corner points $( \pm p, \pm p, \ldots, \pm p)$ are computed for $6 \leq v \leq 15$ using an SUBA with two unequal block sizes in the second order response surface design. The results are given in Tables 1 and 2 in the Appendix.

The variances of estimates of responses $\hat{Y}_{u}$ and slopes $\frac{\partial \hat{Y}_{u}}{\partial x_{i}}$ are further computed for special values of $p=0.25,0.50,1.00,2.00$ in the case of axial and cube corner points besides the central points in all the above designs, and the numerical results regarding the comparative efficiencies of the above designs are given in Table 2 in the Appendix.

On the basis of this analysis certain broad conclusions are drawn regarding the efficiencies of the above designs for the estimation of responses and slopes, and certain practical recommendations are made in this connection regarding the choice of a suitable design (design with lower variance) for the estimation of responses and slopes at central, axial and cube corner points.

\section{Conclusion}

There is no uniform best design for the estimation of responses and slopes at central points, axial points and cube corner points on the second order response surface for different values of $v$ and $p$. However, the following broad conclusions can be drawn from the analysis of Table 2 in the Appendix.

1. For the estimation of responses at the central point, axial points and cube corner points, SOSRD using a SUBA with two unequal block sizes seems to be the preferable design.

2. For the estimation of slopes, (i) at the central points all designs are equally good, (ii) at axial points, EDSOSRD using a SUBA with two unequal block sizes seems to be generally the preferable design, and (iii) at cube corner points, SOSRD using an SUBA with two unequal block sizes seems to be generally the preferable design.

Thus for simultaneous estimation of responses and slopes at central, axial and cube corner points, EDSOSRD using an SUBA with two unequal block sizes seems to be generally the preferable design from this limited study.

\section{Acknowledgements}

The authors are very much thankful to the referees, Associate Editor and the Editor for their constructive suggestions, which have very much improved the earlier version of this paper. The authors are also thankful to Professor V. L. Narasimham for his general guidance. 


\section{Appendix}

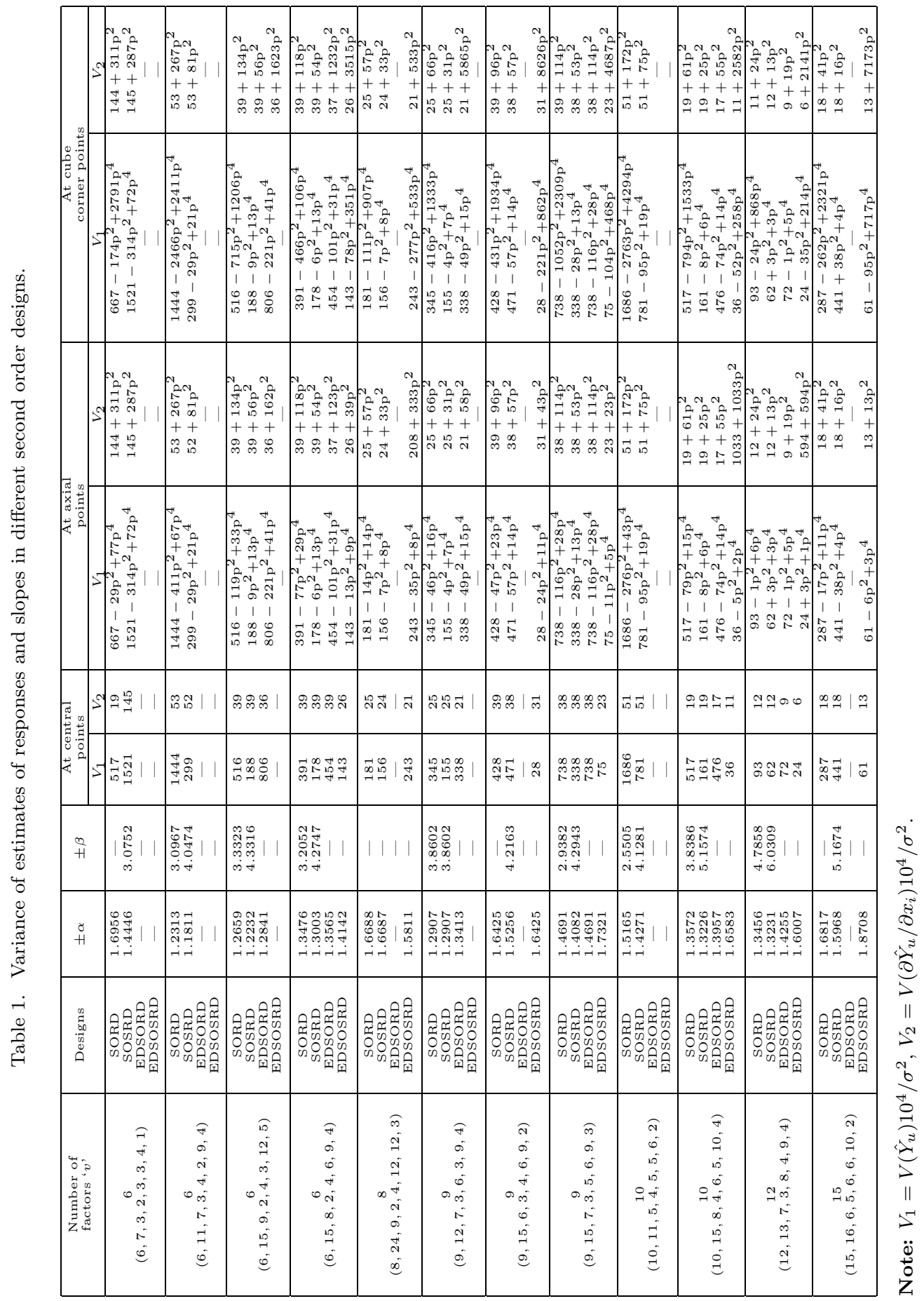


Table 2. Designs with lowest variances for the estimation of responses and slopes.

\begin{tabular}{|c|c|c|c|c|c|c|c|}
\hline \multirow[b]{2}{*}{ Number of factors ' $v$ ' } & \multirow[b]{2}{*}{$p$} & \multicolumn{3}{|c|}{ For estimation of responses } & \multicolumn{3}{|c|}{ For estimation of slopes } \\
\hline & & $\begin{array}{l}\text { Central } \\
\text { points }\end{array}$ & $\begin{array}{l}\text { Axial } \\
\text { points }\end{array}$ & $\begin{array}{l}\text { Cube } \\
\text { corner } \\
\text { points }\end{array}$ & $\begin{array}{l}\text { Central } \\
\text { points }\end{array}$ & $\begin{array}{l}\text { Axial } \\
\text { points }\end{array}$ & $\begin{array}{c}\text { Cube } \\
\text { corner } \\
\text { points }\end{array}$ \\
\hline $\begin{array}{c}6 \\
(6,7,3,2,3,3,4,1)\end{array}$ & $\begin{array}{l}0.25 \\
0.50 \\
1.00 \\
2.00\end{array}$ & $\begin{array}{l}\text { all designs } \\
\text { are equally } \\
\text { efficient }\end{array}$ & $\begin{array}{c}\text { SORD } \\
\text { SORD } \\
\text { SORD } \\
\text { SOSRD }\end{array}$ & $\begin{array}{l}\text { SOSRD } \\
\text { SOSRD } \\
\text { SOSRD } \\
\text { SOSRD } \\
\end{array}$ & $\begin{array}{l}\text { all designs } \\
\text { are equally } \\
\text { efficient }\end{array}$ & $\begin{array}{l}\text { SOSRD } \\
\text { SOSRD } \\
\text { SOSRD } \\
\text { SOSRD }\end{array}$ & $\begin{array}{l}\text { SOSRD } \\
\text { SOSRD } \\
\text { SOSRD } \\
\text { SOSRD }\end{array}$ \\
\hline $\begin{array}{c}6 \\
(6,11,7,3,4,2,9,4)\end{array}$ & $\begin{array}{l}0.25 \\
0.50 \\
1.00 \\
2.00\end{array}$ & $\begin{array}{l}\text { all designs } \\
\text { are equally } \\
\text { efficient }\end{array}$ & $\begin{array}{l}\text { SOSRD } \\
\text { SOSRD } \\
\text { SOSRD } \\
\text { SOSRD }\end{array}$ & $\begin{array}{l}\text { SOSRD } \\
\text { SOSRD } \\
\text { SOSRD } \\
\text { SOSRD }\end{array}$ & $\begin{array}{l}\text { all designs } \\
\text { are equally } \\
\text { efficient }\end{array}$ & $\begin{array}{l}\text { SOSRD } \\
\text { SOSRD } \\
\text { SOSRD } \\
\text { SOSRD }\end{array}$ & $\begin{array}{l}\text { SOSRD } \\
\text { SOSRD } \\
\text { SOSRD } \\
\text { SOSRD }\end{array}$ \\
\hline $\begin{array}{c}6 \\
(6,15,9,2,4,3,1,2,5)\end{array}$ & $\begin{array}{l}0.25 \\
0.50 \\
1.00 \\
2.00\end{array}$ & $\begin{array}{l}\text { all designs } \\
\text { are equally } \\
\text { efficient }\end{array}$ & $\begin{array}{l}\text { SOSRD } \\
\text { SOSRD } \\
\text { SOSRD } \\
\text { SOSRD }\end{array}$ & $\begin{array}{l}\text { SOSRD } \\
\text { SOSRD } \\
\text { SOSRD } \\
\text { SOSRD }\end{array}$ & $\begin{array}{l}\text { all designs } \\
\text { are equally } \\
\text { efficient }\end{array}$ & $\begin{array}{l}\text { SOSRD } \\
\text { SOSRD } \\
\text { SOSRD } \\
\text { SOSRD }\end{array}$ & $\begin{array}{l}\text { SOSRD } \\
\text { SOSRD } \\
\text { SOSRD } \\
\text { SOSRD }\end{array}$ \\
\hline $\begin{array}{c}6 \\
(6,15,8,2,4,6,9,4)\end{array}$ & $\begin{array}{l}0.25 \\
0.50 \\
1.00 \\
2.00\end{array}$ & $\begin{array}{l}\text { all designs } \\
\text { are equally } \\
\text { efficient }\end{array}$ & $\begin{array}{l}\text { EDSOSRD } \\
\text { EDSOSRD } \\
\text { EDSOSRD } \\
\text { EDSOSRD }\end{array}$ & $\begin{array}{c}\text { SOSRD } \\
\text { EDSOSRD } \\
\text { SOSRD } \\
\text { SOSRD }\end{array}$ & $\begin{array}{l}\text { all designs } \\
\text { are equally } \\
\text { efficient }\end{array}$ & $\begin{array}{l}\text { EDSOSRD } \\
\text { EDSOSRD } \\
\text { EDSOSRD } \\
\text { EDSOSRD }\end{array}$ & $\begin{array}{l}\text { SOSRD } \\
\text { SOSRD } \\
\text { SOSRD } \\
\text { SOSRD }\end{array}$ \\
\hline $\begin{array}{c}8 \\
(8,24,9,2,4,12,12,3)\end{array}$ & $\begin{array}{l}0.25 \\
0.50 \\
1.00 \\
2.00\end{array}$ & $\begin{array}{l}\text { all designs } \\
\text { are equally } \\
\text { efficient }\end{array}$ & $\begin{array}{c}\text { SOSRD } \\
\text { SOSRD } \\
\text { SOSRD } \\
\text { EDSOSRD }\end{array}$ & $\begin{array}{l}\text { SOSRD } \\
\text { SOSRD } \\
\text { SOSRD } \\
\text { SOSRD }\end{array}$ & $\begin{array}{l}\text { all designs } \\
\text { are equally } \\
\text { efficient }\end{array}$ & $\begin{array}{l}\text { EDSOSRD } \\
\text { SOSRD } \\
\text { EDSOSRD } \\
\text { EDSOSRD }\end{array}$ & $\begin{array}{l}\text { SOSRD } \\
\text { SOSRD } \\
\text { SOSRD } \\
\text { SOSRD }\end{array}$ \\
\hline $\begin{array}{c}9 \\
(9,12,7,3,6,3,9,4)\end{array}$ & $\begin{array}{l}0.25 \\
0.50 \\
1.00 \\
2.00\end{array}$ & $\begin{array}{l}\text { all designs } \\
\text { are equally } \\
\text { efficient }\end{array}$ & $\begin{array}{l}\text { SOSRD } \\
\text { SOSRD } \\
\text { SOSRD } \\
\text { SOSRD }\end{array}$ & $\begin{array}{l}\text { SOSRD } \\
\text { SOSRD } \\
\text { SOSRD } \\
\text { SOSRD }\end{array}$ & $\begin{array}{l}\text { all designs } \\
\text { are equally } \\
\text { efficient }\end{array}$ & $\begin{array}{l}\text { EDSORD } \\
\text { SOSRD } \\
\text { SOSRD } \\
\text { SOSRD }\end{array}$ & $\begin{array}{c}\text { EDSOSRD } \\
\text { SOSRD } \\
\text { SOSRD } \\
\text { SOSRD }\end{array}$ \\
\hline $\begin{array}{c}9 \\
(9,15,6,3,4,6,9,2)\end{array}$ & $\begin{array}{l}0.25 \\
0.50 \\
1.00 \\
2.00\end{array}$ & $\begin{array}{l}\text { all designs } \\
\text { are equally } \\
\text { efficient }\end{array}$ & $\begin{array}{l}\text { EDSOSRD } \\
\text { EDSOSRD } \\
\text { EDSOSRD } \\
\text { EDSOSRD }\end{array}$ & $\begin{array}{c}\text { EDSOSRD } \\
\text { EDSOSRD } \\
\text { SOSRD } \\
\text { SOSRD }\end{array}$ & $\begin{array}{l}\text { all designs } \\
\text { are equally } \\
\text { efficient }\end{array}$ & $\begin{array}{l}\text { EDSOSRD } \\
\text { EDSOSRD } \\
\text { EDSOSRD } \\
\text { EDSOSRD }\end{array}$ & $\begin{array}{l}\text { EDSOSRD } \\
\text { EDSOSRD } \\
\text { EDSOSRD } \\
\text { EDSOSRD }\end{array}$ \\
\hline $\begin{array}{c}9 \\
(9,15,7,3,5,6,9,3)\end{array}$ & $\begin{array}{l}0.25 \\
0.50 \\
1.00 \\
2.00\end{array}$ & $\begin{array}{l}\text { all designs } \\
\text { are equally } \\
\text { efficient }\end{array}$ & $\begin{array}{l}\text { EDSOSRD } \\
\text { EDSOSRD } \\
\text { EDSOSRD } \\
\text { EDSOSRD }\end{array}$ & $\begin{array}{c}\text { EDSOSRD } \\
\text { EDSOSRD } \\
\text { SOSRD } \\
\text { SOSRD }\end{array}$ & $\begin{array}{l}\text { all designs } \\
\text { are equally } \\
\text { efficient }\end{array}$ & $\begin{array}{l}\text { EDSOSRD } \\
\text { EDSOSRD } \\
\text { EDSOSRD } \\
\text { EDSOSRD }\end{array}$ & $\begin{array}{c}\text { SOSRD } \\
\text { SOSRD } \\
\text { SOSRD } \\
\text { EDSORD }\end{array}$ \\
\hline $\begin{array}{c}10 \\
(10,11,5,4,5,5,6,2)\end{array}$ & $\begin{array}{l}0.25 \\
0.50 \\
1.00 \\
2.00\end{array}$ & $\begin{array}{l}\text { all designs } \\
\text { are equally } \\
\text { efficient }\end{array}$ & $\begin{array}{l}\text { SOSRD } \\
\text { SOSRD } \\
\text { SOSRD } \\
\text { SOSRD }\end{array}$ & $\begin{array}{l}\text { SOSRD } \\
\text { SOSRD } \\
\text { SOSRD } \\
\text { SOSRD }\end{array}$ & $\begin{array}{l}\text { all designs } \\
\text { are equally } \\
\text { efficient }\end{array}$ & $\begin{array}{l}\text { SOSRD } \\
\text { SOSRD } \\
\text { SOSRD } \\
\text { SOSRD }\end{array}$ & $\begin{array}{l}\text { SOSRD } \\
\text { SOSRD } \\
\text { SOSRD } \\
\text { SOSRD }\end{array}$ \\
\hline $\begin{array}{c}10 \\
(10,15,8,4,6,5,10,4)\end{array}$ & $\begin{array}{l}0.25 \\
0.50 \\
1.00 \\
2.00\end{array}$ & $\begin{array}{l}\text { all designs } \\
\text { are equally } \\
\text { efficient }\end{array}$ & $\begin{array}{l}\text { EDSOSRD } \\
\text { EDSOSRD } \\
\text { EDSOSRD } \\
\text { EDSOSRD }\end{array}$ & $\begin{array}{c}\text { EDSOSRD } \\
\text { EDSOSRD } \\
\text { SOSRD } \\
\text { SOSRD }\end{array}$ & $\begin{array}{l}\text { all designs } \\
\text { are equally } \\
\text { efficient }\end{array}$ & $\begin{array}{l}\text { EDSOSRD } \\
\text { EDSOSRD } \\
\text { EDSOSRD } \\
\text { EDSOSRD }\end{array}$ & $\begin{array}{c}\text { EDSORD } \\
\text { SOSRD } \\
\text { SOSRD } \\
\text { SOSRD }\end{array}$ \\
\hline $\begin{array}{c}12 \\
(12,13,7,3,8,4,9,4)\end{array}$ & $\begin{array}{l}0.25 \\
0.50 \\
1.00 \\
2.00\end{array}$ & $\begin{array}{l}\text { all designs } \\
\text { are equally } \\
\text { efficient }\end{array}$ & $\begin{array}{l}\text { EDSOSRD } \\
\text { EDSOSRD } \\
\text { EDSOSRD } \\
\text { EDSOSRD }\end{array}$ & $\begin{array}{c}\text { EDSOSRD } \\
\text { EDSOSRD } \\
\text { SOSRD } \\
\text { SOSRD }\end{array}$ & $\begin{array}{l}\text { all designs } \\
\text { are equally } \\
\text { efficient }\end{array}$ & $\begin{array}{l}\text { EDSOSRD } \\
\text { EDSOSRD } \\
\text { EDSOSRD } \\
\text { EDSOSRD }\end{array}$ & $\begin{array}{l}\text { SOSRD } \\
\text { SOSRD } \\
\text { SOSRD } \\
\text { SOSRD }\end{array}$ \\
\hline $\begin{array}{c}15 \\
(15,16,6,5,6,6,10,2)\end{array}$ & $\begin{array}{l}0.25 \\
0.50 \\
1.00 \\
2.00\end{array}$ & $\begin{array}{l}\text { all designs } \\
\text { are equally } \\
\text { efficient }\end{array}$ & $\begin{array}{l}\text { EDSOSRD } \\
\text { EDSOSRD } \\
\text { EDSOSRD } \\
\text { EDSOSRD }\end{array}$ & $\begin{array}{c}\text { EDSOSRD } \\
\text { EDSOSRD } \\
\text { SOSRD } \\
\text { SOSRD }\end{array}$ & $\begin{array}{l}\text { all designs } \\
\text { are equally } \\
\text { efficient }\end{array}$ & $\begin{array}{l}\text { EDSOSRD } \\
\text { EDSOSRD } \\
\text { EDSOSRD } \\
\text { EDSOSRD }\end{array}$ & $\begin{array}{l}\text { EDSOSRD } \\
\text { EDSOSRD } \\
\text { EDSOSRD } \\
\text { EDSOSRD }\end{array}$ \\
\hline
\end{tabular}




\section{REFERENCES}

Box, G. E. P. and Hunter, J. S. (1957). Multifactor experimental designs for exploring response surfaces, Annals of Mathematical Statistics, 28, 195-241.

Das, M. N. and Narasimham, V. L. (1962). Construction of rotatable designs through balanced incomplete block designs, Annals of Mathematical Statistics, 33, 1421-1439.

Dey, A. (1970). On response surface designs with equi-spaced doses, Calcutta Statistical Association Bulletin, 19, 135-144.

Hader, R. J. and Park, S. H. (1978). Slope rotatable central composite designs, Technometrics, 20, 413-417.

Raghavarao, D. (1962). Symmetrical unequal block arrangements with two unequal block sizes, Annals of Mathematical Statistics, 33, 620-633.

Raghavarao, D. (1963). Construction of second order rotatable designs through incomplete block designs, Journal of Indian Statistical Association, 1, 221-225.

Raghavarao, D. (1971). Constructions and Combinatorial Problems in Design of Experiments, John Wiley, New York.

Victorbabu, B. Re. (2002a). Second order slope rotatable designs with equi-spaced levels, Proceedings of Andhra Pradesh Akademi of Sciences, 6, 211-214.

Victorbabu, B. Re. (2002b). Construction of second order slope rotatable designs using symmetrical unequal block arrangements with two unequal block sizes, Journal of the Korean Statistical Society, 31, 153-161.

Victorbabu, B. Re. (2007). On second order slope rotatable designs - A review, Journal of the Korean Statistical Society, 36, 373-386.

Victorbabu, B. Re. and Narasimham, V. L. (1991). Construction of second order slope rotatable designs through balanced incomplete block designs, Communications in Statistics - Theory and Methods, 20, 2467-2478.

Victorbabu, B. Re. and Vasundharadevi, V. (2004). On the efficiency of second order response surface designs for estimation of responses and slopes using balanced incomplete block designs, Statistical Methods, 6, 210-224.

Victorbabu, B. Re., Narayanarao, E. S. V. and Narasimham, V. L. (1994). Construction of second order slope rotatable designs with equi-spaced levels using incomplete block designs with unequal block sizes, Proceedings of the XV Indian Society for Probability and Statistics Conference, M.S. University, Tirunelveli-627 009, India, 116-119. 